\title{
Time Trends in the Incidence and Mortality of Ovarian Cancer in Ireland, Northern Ireland, and Israel, 1994-2013
}

\author{
Lital Keinan-Boker, MD, * $+\$$ Barbara G. Silverman, MD, $\dagger \S$ Paul M. Walsh, PhD,// \\ Anna T. Gavin, MD, $\mathbb{I}$ and Catherine Hayes, MD
}

\begin{abstract}
Objectives: The aims of this study were to compare time trends in ovarian cancer incidence and mortality in populations with (1) similar genetics but different health care systems (Ireland and Northern Ireland [NI]) and (2)different genetics but similar health care system (Israeli Jews and Arabs) and to interpret the results.

Methods: Age-standardized rates of ovarian cancer incidence and mortality for 1994-2013 in the 3 countries were obtained from national cancer registries and national statistics. Time trends in incidence, mortality, and incidence-to-mortality ratio were assessed by linear regression models applied to each country and between populations (Ireland-NI, Ireland-Israeli Jews, Israeli Jews-Arabs). Joinpoint analysis was used to calculate the annual percentage change (APC).

Results: Ovarian cancer incidence and mortality rates in 1994 were similar in the countries studied. Thereafter a reduction in incidence and mortality was observed in Ireland (incidence $\mathrm{APC}_{1994-2013}=-0.75 \%, P<0.05$; mortality $\left.\mathrm{APC}_{1994-2013}=-0.67 \%, P<0.05\right)$, NI (incidence $\mathrm{APC}_{1998-2013}=-1.5 \%, P<0.05$; mortality $\mathrm{APC}_{2005-2013}=-3.8 \%, P<0.05$ ), and Israeli Jews (incidence $\mathrm{APC}_{1994-2013}=-2.2 \%, P<0.05$; mortality $\mathrm{APC}_{1994-2013}=$ $-1.2 \%, P<0.05)$. Trends in Israeli Arabs remained stable. Significant incidence trend differences between Ireland and Israeli Jews $(P=0.009)$ and between Israeli Jews and Arabs $(P=0.004)$ were observed. The only significant trend difference for mortality was between Israeli Jews and Arabs $(P=0.038)$. Incidence-to-mortality ratios showed stable trends in all groups except for Israeli Jews $\left(\mathrm{APC}_{1994-2013}=-1.0 \%, P<0.05\right)$.

Conclusions: Time trends in ovarian cancer incidence (decreasing) and mortality (decreasing) were similar in Ireland, NI, and Israeli Jews, following global trends, with a more prominent incidence decline in Israeli Jews. Decreasing mortality trends are driven by falling incidence in the countries studied rather than improved survival.
\end{abstract}

Key Words: Incidence trends, Ireland, Israel, Mortality trends, Northern Ireland, Ovarian cancer

Received December 18, 2016, and in revised form March 19, 2017.

Accepted for publication June 7, 2017.

(Int J Gynecol Cancer 2017;00: 00-00)

*School of Public Health, Faculty of Social Welfare and Health Sciences, University of Haifa, Haifa; and †Israel Center for Disease Control, Israel Ministry of Health, Ramat Gan, Israel; $\$$ Public Health and Primary Care, Institute for Population Health, Trinity College Dublin Education Centre, Tallaght Cross, Dublin, Ireland; $\S$ School of Public Health, Sackler Faculty of Medicine, Tel Aviv University, Tel Aviv, Israel; |National Cancer Registry Ireland, Cork, Ireland; and $\mathbb{\uparrow N o r t h e r n ~ I r e l a n d ~ C a n c e r ~ R e g i s t r y , ~ C e n t r e ~ f o r ~}$

Copyright (C) 2017 by IGCS and ESGO

ISSN: $1048-891 \mathrm{X}$

DOI: $10.1097 /$ IGC.0000000000001079
Public Health, Queen's University Belfast, Belfast, Northern Ireland, United Kingdom.

Address correspondence and reprint requests to Lital Keinan-Boker, MD, PhD, MPH School of Public Health, Faculty of Social Welfare and Health Sciences, University of Haifa, 199 Abba Hushy Blvd., Haifa 31905, Israel. E-mail: 1keinan@, univ.haifa.ac.il; lital.keinan2@moh.health.gov.il.

L.K.-B. was a visiting professor.

The authors declare no conflicts of interest.

Supplemental digital content is available for this article. Direct URL citation appears in the printed text and is provided in the HTML and PDF versions of this article on the journal's Web site (www.ijgc.net). 
$\mathrm{O}$ varian cancer is diagnosed annually in nearly 250,000 women worldwide and is responsible for approximately 140,000 deaths. ${ }^{1}$ It is often referred to as the "silent killer" because of late symptomatic presentation. Based on Globocan 2012 estimates, Ireland ranked 14th (age-standardized rate $[\mathrm{ASR}]=11.2 / 100,000)$, and the United Kingdom including Northern Ireland $(\mathrm{NI})$ ranked 10th $(\mathrm{ASR}=11.7 / 100,000)$ globally with respect to ovarian cancer incidence. Israel ranked lower, with an ASR of 7.3 per $100,000 .^{2}$

Approximately $90 \%$ of ovarian tumors are epithelial in origin. Germ cell tumors, more common among younger patients, account for approximately $2.5 \% .^{3,4}$ As the disease is generally advanced when it is diagnosed, relative 5-year survival ranges from $30 \%$ to $50 \%{ }^{1,2}$ Population-based screening has not as yet demonstrated a definitive mortality reduction, ${ }^{5}$ although the UK Collaborative Trial of Ovarian Cancer Screening recently reported that annual multimodal screening with serum CA-125 together with a risk-based algorithm shows some promise. ${ }^{6}$

Risk factors/markers for the disease include advanced age, certain genetic mutations (eg, $B R C A$ genes), positive family history of ovarian or breast cancer, reproductive factors (early menarche, late menopause, older age at first childbirth, infertility/nulliparity, no breastfeeding), never use of oral contraceptives (OCs), use of hormonal therapy (HT), and obesity. ${ }^{4}$ However, the disease etiology remains largely unknown.

Comparative analysis of cancer incidence, mortality, and time trends in populations that differ by exposures, lifestyles, and health care access may aid in understanding disease patterns. Ireland, ${ }^{7} \mathrm{NI},{ }^{8}$ and Israel $^{9}$ have different public health systems with reasonable access to health care. The populations in the 3 countries also differ by certain exposures, lifestyles, and genetic predisposition. The setting of the 3 countries allows comparison between genetically homogenous populations living in the same geographic location (Island of Ireland), but under 2 different jurisdictions with differing health systems (Republic of Ireland and United Kingdom) and 2 genetically different populations (Israeli Jews and Arabs) in the same geographic location (the State of Israel), sharing a universal health care system.

The aims of the current report were to compare trends in ovarian cancer incidence and mortality in the period 1994-2013 in Ireland, NI, and Israel and to suggest possible explanations for any observed differences.

\section{METHODS}

This is a comparative study of longitudinal trends in ovarian cancer incidence and mortality over a 20 -year-period in 3 countries.

\section{Study Population}

The total female population in Ireland, NI, and Israel for the years 1994-2013 served as the study population. Populations by age group and year were obtained from the Central Statistics Office (Ireland), ${ }^{10}$ Northern Ireland Statistics and Research Agency, ${ }^{11}$ and Central Bureau of Statistics (Israel). ${ }^{12}$

\section{Study Variables}

Age-standardized rates of ovarian cancer incidence and mortality and incidence-to-mortality (I/M) ratios from 1994 through 2013 were calculated for each population, using the European standard population distribution by 5-year age groups, truncated at age 74 years and supplemented with an age group of 75 years or older. ${ }^{13}$

\section{Incidence Data}

Incidence rates of invasive ovarian cancer (topographic code C-56, behavior 3, third edition of the International Classification of Diseases for Oncology) were obtained from the respective national cancer registries. 11,14,15 "Borderline" cystadenomas of the ovary were coded in the 3 registries as being of uncertain behavior status using the third edition of the International Classification of Diseases for Oncology and were excluded from the current analysis.

All 3 cancer registries-National Cancer Registry Ireland (established 1991), Northern Ireland Cancer Registry (NICR) (established 1994), and Israel National Cancer Registry (established 1960)-are population-based registries, collecting and classifying information on all cancer cases. The completeness of the National Cancer Registry Ireland, NICR, and Israel National Cancer Registry with respect to solid malignant tumors is estimated as $95 \%, 98 \%$, and $94 \%$, respectively. ${ }^{11,14,15}$

\section{Mortality Data}

Numbers and rates of ovarian cancer deaths (C56 International Classification of Diseases, 10th Revision) were obtained from Central Statistics Office (Ireland) and Central Bureau of Statistics (Israel). Both bodies code the main cause of death as reported on the death certificate using the International Classification of Diseases, 10th Revision (Internain Ireland pre-2007). Data on NI ovarian cancer deaths were obtained directly from NICR, which receives data from the General Registrar's Office.

The available Irish mortality data required age standardization, which was carried out using the direct standardization method. Data for NI and for Israel were provided in agestandardized format (using the same standard population). A weighted mean was computed for age group 75 years or older in NI based on the age distribution in the NI population (75-79 years: $2.8 \%$ of total population; $80-84$ years: $2.0 \%$; $85-89$ years: $1.2 \%$; $\geq 90$ years: $0.6 \%$ ) to harmonize the age group structure across the 3 data sets.

\section{Incidence-to-Mortality Ratio}

The I/M ratios were used as proxies for case-fatality trends and were expressed per each calendric year.

\section{Data Analysis}

Numbers and ASRs are presented for ovarian cancer incidence and mortality for the years 1994-2013. Israeli data are presented separately for Jews and Arabs.

Linear regression models were used to assess time trends in annual rates for the period 1994-2013 in each country and within populations. The null hypothesis stated that the slope of the regression line was not significantly different from 
$0(P<0.05)$. Differences between populations (Ireland and Israeli Jews, Ireland and NI, Israeli Jews and Arabs), deltas, were computed and used as the dependent variable in the regression model.

The Joinpoint software was used to appreciate time trends in a structured manner; the program fits the simplest linear model, that is, the lowest possible number of lines $(0-3)$ that are connected together at the "joinpoints" that the data allow. The program also tests which trends (between joinpoints) are statistically significant. The software allowed the calculation of mean annual percentage change (APC) of incidence and mortality over time. ${ }^{16}$

Analyses were carried out using Excel for Windows (Microsoft Excel for Mac 2011, version 14.1.0 (110310) or Joinpoint software, as applicable.

\section{RESULTS}

\section{Ovarian Cancer Incidence Trends, 1994-2013}

Ovarian cancer incidence trends, 1994-2013, are shown in Supplemental Appendix Table 1 (http://links.lww.com/IGC/ A528) and Figure 1.

Ovarian cancer mean incidence for 1994-2003 in Ireland was 328 cases per year (range, 262-384 cases per year). Incidence rates decreased over time, from 15.6 per 100,000 in 1994 to 13.7 per 100,000 in $2013\left(P_{\text {trend }}=0.01\right)$. Joinpoint analysis confirmed an estimated average APC of $-0.75 \%(P=0.01)$.

In NI, ovarian cancer mean incidence for 1994-2003 was 179 cases per year (range, 142-208 cases per year). Time trends appeared to remain stable, with respect to incidence rates: 16.7 per 100,000 in $1994,18.3$ per 100,000 in 2013 $\left(P_{\text {trend }}=0.19\right)$. Joinpoint analysis showed that from 1994 to 1998 the trend nonsignificantly increased $(\mathrm{APC}=+6.4 \%, P=$ 0.09), whereas from 1998 to 2013 a significant decrease was observed (APC $=-1.5 \%(P=0.005)$.

In Israeli Jewish women, ovarian cancer mean incidence for 1994-2003 was 324 cases per year (range, 286-347 cases per year). A significant decrease in incidence rates was evident over time: from 16.1 per 100,000 in 1994 to 10.4 per 100,000 in 2013 ( $\left.P_{\text {trend }}<0.001\right)$, confirmed by Joinpoint analysis (APC $=-2.2 \%, P<0.00001)$. In Israeli Arab women, ovarian cancer mean incidence for 1994-2003 was considerably lower, 21 cases per year (range, 10-35 cases per year). The incidence rates did not substantially change over time $\left(P_{\text {trend }}=0.35\right)$, and the Joinpoint APC was $+0.93(P=$ $0.36)$.

Although a significant decreasing trend in ovarian cancer incidence was noted for both Irish women and Israeli Jewish women, the rate of decrease was lower in Ireland $(P=$ $0.009)$. Trends did not substantially differ $(P=0.73)$ between Ireland and NI, but differed significantly between Israeli Jews and Arabs $(P=0.004)$

Ovarian cancer incidence rates increased with age in the 3 countries. In 2013, the highest age-specific incidence rates were observed in the age group 75 years or older in all except for Israeli Arab women, in whom the highest rates were observed in 60- to 64-year-olds. Age-specific rates were higher in Ireland and NI compared with Israel (Jews and Arabs) within all age groups and especially at older ages (Fig. 2).

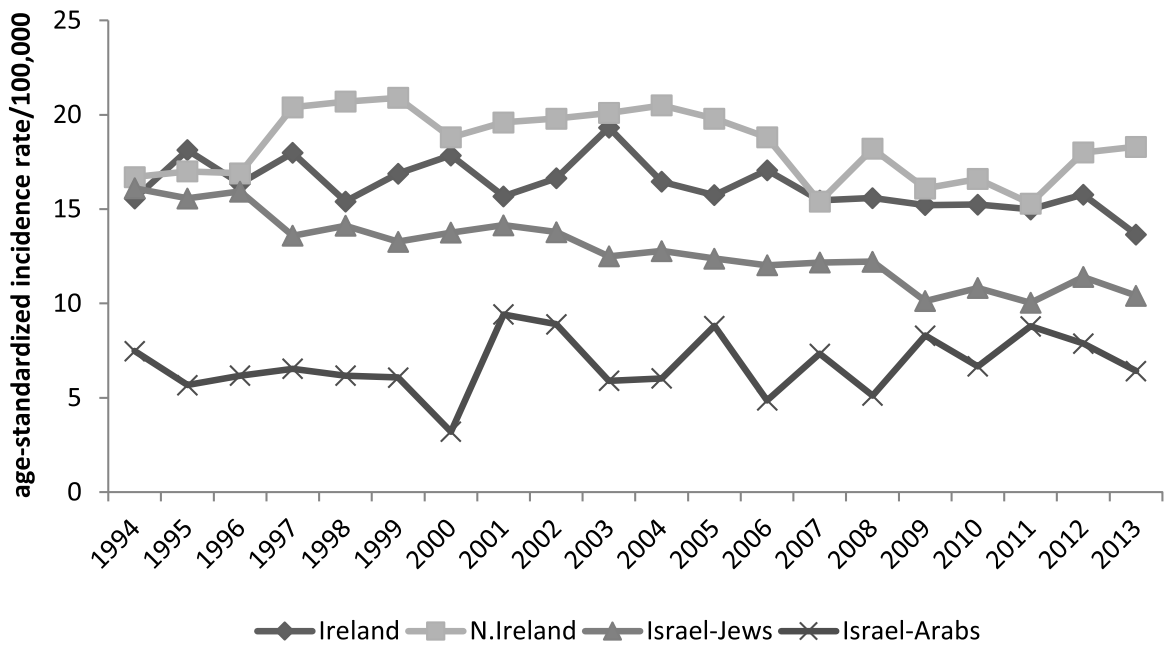

Annual percentage change (APCs), where * denotes statistical significance level<0.05, were: Ireland $=-0.75 \% *(1994-2013)$

Northern Ireland=+6.41\% (1994-1998); =-1.51\%* (1998-2013)

Israel/Jews=-2.22\%* (1994-2013)

Israel/Arabs $=+0.93 \%(1994-2013)$

FIGURE 1. Ovarian cancer incidence trends in women in Ireland, NI, and Israel (Jewish and Arab), $1994-2013$. 
Ovarian cancer age-specific incidence rates, 2013, by country

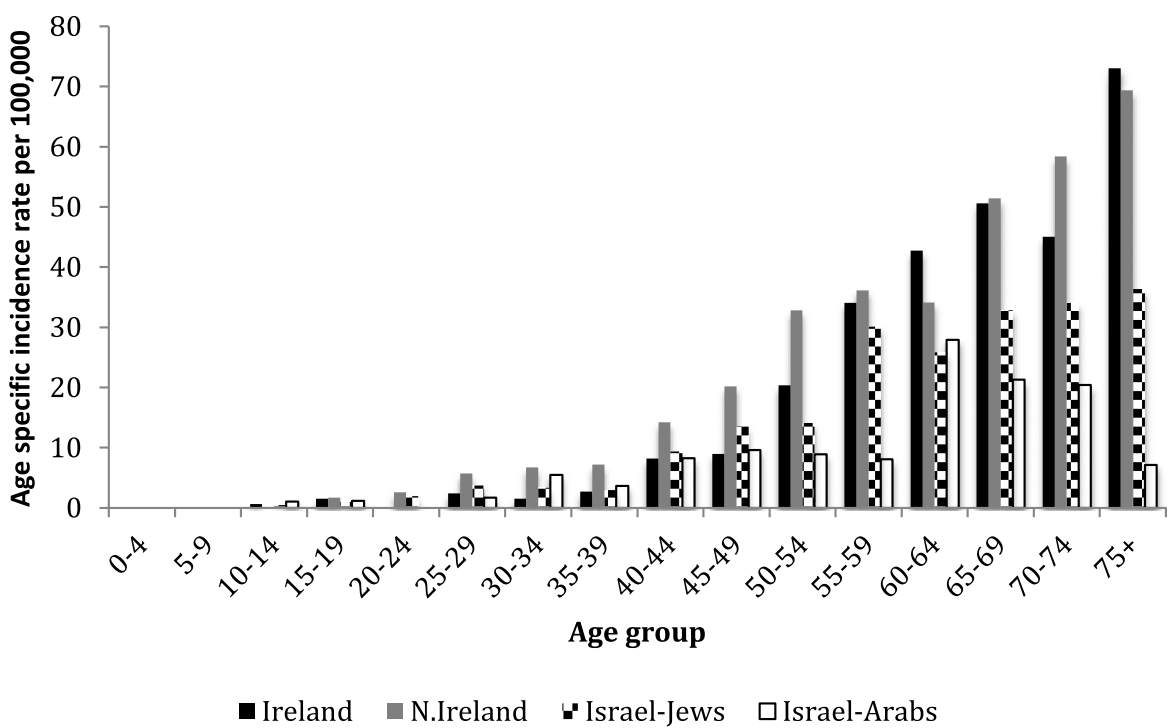

FIGURE 2. Ovarian cancer age-specific incidence rates in women in Ireland, NI, and Israel (Jewish and Arab), 2013.

\section{Ovarian Cancer Mortality Trends, 1994-2013}

Ovarian cancer mortality trends, 1994-2013, are shown in Supplemental Appendix Table 2 (http://links.lww.com/ IGC/A528) and Figure 3.

Ovarian cancer mean mortality for the years 1994-2013 in Ireland was 244 cases per year (range, 200-286 cases per year). Mortality rates decreased significantly over time from 11.8 per 100,000 in 1994 to 10.2 per 100,000 in 2013 $\left(P_{\text {trend }}=0.04\right)$. Joinpoint analysis confirmed an APC $=$ $-0.67 \%(P=0.038)$.

In NI, ovarian cancer mean mortality for the years 1994-2013 was 112 cases per year (range, 89-136 cases per year). The overall time trend of mortality rates appeared stable: 9.5 per 100,000 in 1994 and 9.9 per 100,000 in $2013\left(P_{\text {trend }}=\right.$ 0.45). However, Joinpoint analysis showed that between 1994 and 2005 the trend remained stable: $\mathrm{APC}=+1.8 \%(P=0.077)$,

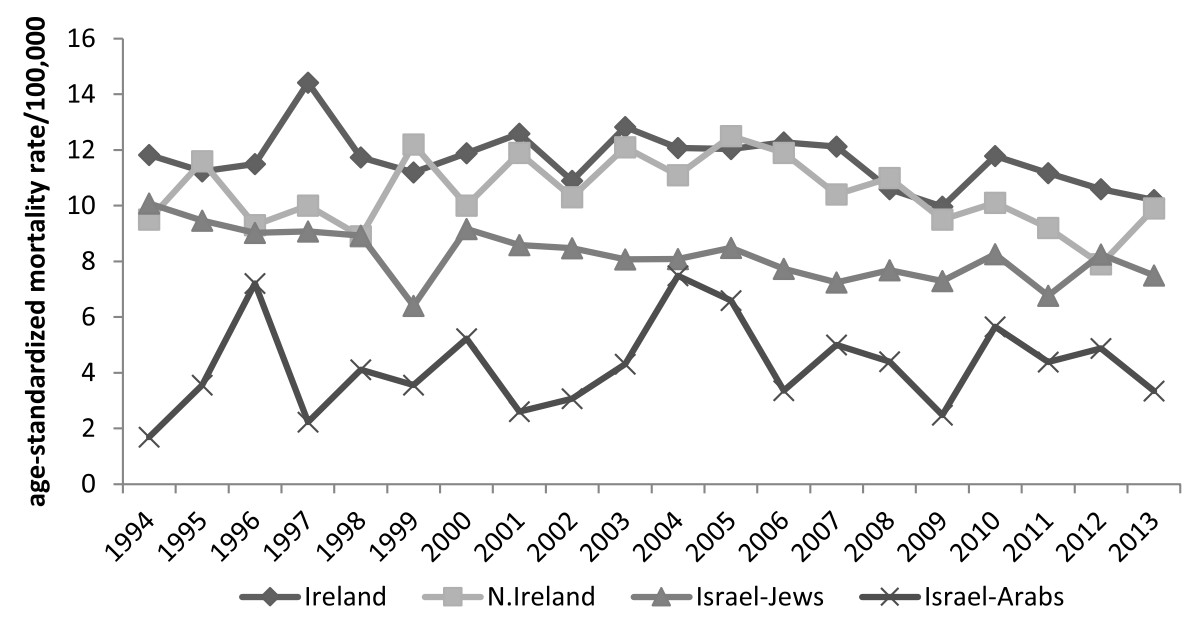

Annual percentage change (APCs), where * denotes statistical significance level<0.05, were: Ireland $=-0.67 \% *(1994-2013)$

Northern Ireland=+1.82\% (1994-2005); =-3.78\%* (2005-2013)

Israel/Jews=-1.22\%* (1994-2013)

Israel/Arabs=+1.75\% (1994-2013)

FIGURE 3. Ovarian cancer mortality trends in women in Ireland, NI, and Israel (Jewish and Arab), 1994-2013. 
whereas from 2005 to 2013 a significant decrease was observed: APC $=-3.8 \%(P=0.024)$.

In Israeli Jewish women, ovarian cancer mean mortality for the years 1994-2013 was 226 cases per year (range, 161-276 cases per year). A decrease in ovarian cancer mortality rates over time was evident: from 10.8 per 100,000 in 1994 to 7.5 per 100,000 in $2013\left(P_{\text {trend }}=0.001\right)$, and Joinpoint analysis confirmed an APC of $-1.2 \%(P=0.003)$. In Israeli Arabs, ovarian cancer mean mortality for the years 1994-2013 was much lower, 11 cases per year (range, 4-18 cases per year). Mortality rates showed that no substantial changes were observed: 1.7 per 100,000 in 1994 and 3.3 per 100,000 in $2013\left(P_{\text {trend }}=0.47\right)$, APC $=+1.8 \%(P=0.268)$.

Differences in time trends between Ireland and NI $(P=$ $0.47)$ and between Ireland and Israeli Jews $(P=0.56)$ were not observed. However, time trends of ovarian cancer mortality differed significantly between Israeli Jewish and Arab women $(P=0.04)$.

Ovarian cancer mortality rates increased with age and in 2013 were highest in women 75 years or older in all study populations except for Israeli Arabs, where the highest rates were observed in 70- to 74-year-olds. Mortality rates in Ireland and NI were higher than rates in Israeli Jews in all age groups, whereas rates for Israeli Arabs were the lowest (Fig. 4).

\section{Ovarian Cancer I/M Ratio Time Trends, 1994-2013}

Ovarian cancer I/M ratio time trends, 1994-2013, are shown in Supplemental Appendix Table 3 (http://links.lww. com/IGC/A528) and Figure 5.

Higher I/M ratio, as proxy for case fatality, indicates lower case fatality. In Ireland, NI, and Israel (Jews) in the years 1994 to 2013 , the ratio was generally low and usually higher in NI.

In Ireland, the I/M ratio did not substantially change over time (1.32 in 1994 and 1.34 in $\left.2013 ; P_{\text {trend }}=0.74\right)$, confirmed by Joinpoint analysis (APC $=-0.09 \%, P=0.782)$.
Similarly, the I/M ratio did not change over time in NI (1.76 in 1994 and 1.85 in 2013; $P_{\text {trend }}=0.79$ ), Joinpoint analysis: $\mathrm{APC}=-0.14 \%(P=0.783)$.

In Israeli Jews, the I/M ratio decreased over time (1.60 in 1994 and 1.39 in 2013; $\left.P_{\text {trend }}=0.008\right), \mathrm{APC}=-1.0 \%(P=$ $0.005)$. Time trends for the $\mathrm{I} / \mathrm{M}$ ratio in Israeli Arabs were nonsignificant $\left(P_{\text {trend }}=0.38\right), \mathrm{APC}=-0.80 \%(P=0.700)$.

\section{DISCUSSION}

We examined time trends over 20 years in ovarian cancer incidence and mortality in 3 countries where incidence and mortality rates in 1994 were similar. Thereafter, a significant reduction in incidence and mortality was observed in Ireland and in Israeli Jews, with similar trends occurring in NI somewhat later. The annual changes (APCs) in disease incidence were generally larger than for mortality. The Israeli Arab population, with low baseline rates of ovarian cancer, showed no changes over time.

The observed decrease in ovarian cancer incidence was significantly more rapid in the Israeli Jewish population compared with Ireland $(P=0.009)$, but mortality trends did not differ between the 2 populations. Although differences in incidence or mortality trends were not observed between Ireland and NI, for Israeli Jews and Arabs significant differences were noted. However, ovarian cancer I/M ratios showed stable trends throughout the study period except in Israeli Jews, in whom a significant decreasing trend was observed $(P<0.05)$.

\section{Incidence Trends}

Decreasing trends in ovarian cancer incidence have been observed in all continents. ${ }^{4,17,18}$ In some countries, the trends were stable, ${ }^{19-22}$ whereas in others they increased. ${ }^{23,24}$ The decreasing incidence trends in Ireland, NI (since 1998), and Israeli Jews are in accordance with observations for other high-background-incidence countries (eg, the United States).

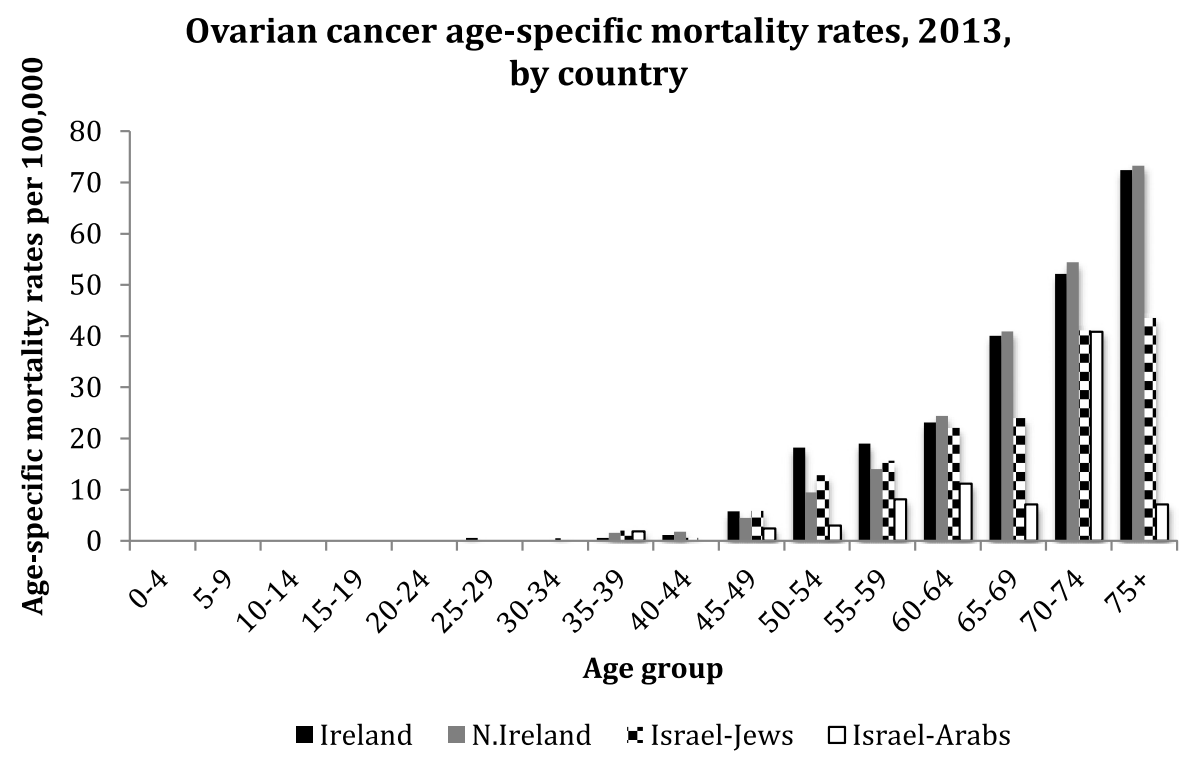

FIGURE 4. Ovarian cancer age-specific mortality rates in women in Ireland, NI, and Israel (Jewish and Arab), 2013. 


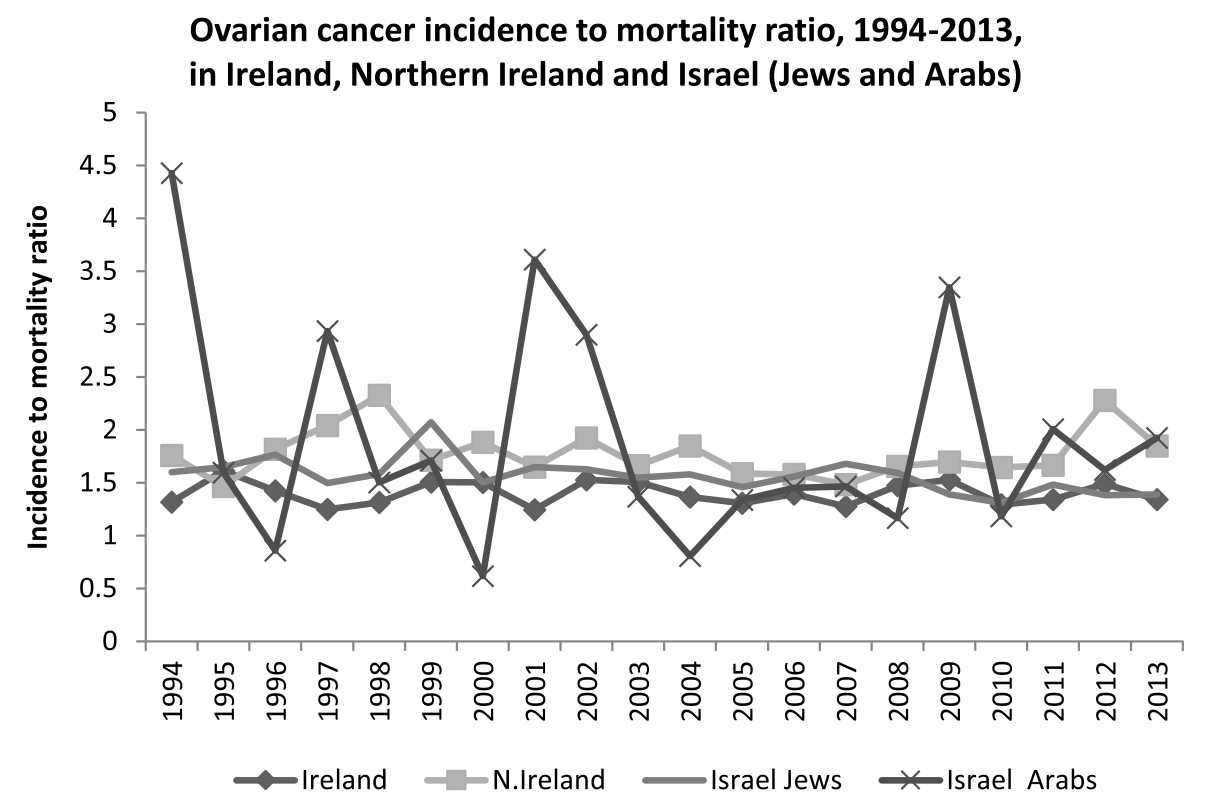

Annual percent change (APCs), where * denotes statistical significance level<0.05, were:
Ireland $=-0.09$ (1994-2013)
Northern Ireland $=-0.14(1994-2013$
Israel Jews $=-1.02 *(1994-2013)$
Israel Arabs $=0.80(1994-2013)$

FIGURE 5. Ovarian cancer I/M ratio in women in Ireland, NI, and Israel (Jewish and Arab), 1994-2013.

Decreases in incidence may be the result of a change in the structure of a population ${ }^{4}$; however, they most likely reflect changing patterns of certain exposures. Use of OCs, pregnancy, and breastfeeding are all associated with reduced risk of ovarian cancer, whereas use of HT and obesity are considered risk factors for the disease. ${ }^{4}$

A recent study affirmed an increasing trend in $\mathrm{OC}$ uptake among women aged 16 to 44 years in Ireland $(27 \%$ in $2002,38 \%$ in $2004,43 \%$ in 2010 ), which is in accordance with UK trends for women aged 16 to 49 years $(44 \%$ in $2008-2009,47 \%$ in $2013-2014) .{ }^{25}$ In Israel, $57 \%$ and $60 \%$ of women aged 21 to 44 years reported ever using OCs in 2003-2004 and in 2007-2008, respectively. ${ }^{26}$

Birth rate (live births per 1000 population) differs between Ireland, NI, and Israel. Birth rate in Ireland decreased from 21.8 in 1980 to 15.1 in 1990, stabilized at 14.5 in 2000, and was 15.0 in $2013 .^{7}$ In NI, the initially higher birth rate decreased from 28.6 (1980) to 26.2 (1990) and 21.5 (2000) and rose to 24.3 in $2013 .{ }^{11}$ Among Israeli Jews, birth rates have remained stable: 21.8 in $1980,18.7$ in $1990,18.7$ in 2000, and 20.7 in 2013. Among Israeli Arabs, however, birth rates have historically been substantially higher than in the Jewish population but have decreased over time: 37.2 in 1980, 34.9 in 1990, 35.0 in 2000, and 23.5 in 2013. ${ }^{12}$

Rates of breastfeeding also differ substantially across study populations. Breastfeeding initiation was reported by $38 \%$ of the mothers in Ireland in $1993^{27}$ and by $56 \%$ in 2013. ${ }^{28} \mathrm{In} \mathrm{NI}$, the reported rate of breastfeeding initiation was approximately $45 \%$ in 1995 and $64 \%$ in $2010 .{ }^{29}$ In Israel, $77 \%$ and $83 \%$ of Jewish and Arab mothers, respectively, initiated breastfeeding in 2009-2010, similar to rates reported a decade earlier. ${ }^{30}$ Exclusive breastfeeding rates at age 6 months, as recommended by the World Health Organization, were $0.7 \%$ in Ireland in $2015^{31}$ and $1 \%$ in the United Kingdom in $2010 .{ }^{32}$ In Israel, rates were $11 \%$ in $1998-1999$ and $22.5 \%$ and $12.3 \%$ in Jewish and Arab mothers, respectively, in 2009-2010. ${ }^{30}$

Use of HT in Ireland based on prescription data significantly decreased, from $19.7 \%$ in 2001 to $12.3 \%$ in $2004,{ }^{33}$ following the publication of findings indicating a higher risk of breast cancer associated with HT use. ${ }^{34,35} \mathrm{In} \mathrm{NI} /$ the United Kingdom, where HT is essentially free of charge, the proportion of women 40 years or older using HT increased substantially, from $8 \%$ in 1991 to $14 \%$ in 1996 , stabilized at approximately $15 \%$ by 2001 , but more than halved by 2005 (7\%). ${ }^{36}$ In Israel, $9.9 \%$ (11.7\% among Jews and $2.9 \%$ among Arabs) of women 50 years or older reported HT use in 2003, lower than the $16.8 \%$ reported in $1998 .{ }^{37}$ Likewise, estrogen product purchases among Israeli women 45 years or older showed a marked decrease from $20 \%$ in 2001 to $10 \%$ in 2007 $(P<0.001){ }^{38}$

Time trends for obesity (defined as body mass index $\geq 30.0 \mathrm{~kg} / \mathrm{m}^{2}$ ) show increases in the 3 countries, but with different background rates. Ireland experienced a substantial increase in obesity (based on self-report): from $13 \%$ of adult women in 2007 to $22 \%$ in $2015 .{ }^{39,40}$ In NI, measured obesity rates in adults also increased with time, from less than $10 \%$ in women aged 16 to 64 years in $1992^{41}$ to $22 \%$ in $2013 .^{42}$ Corresponding rates in Israel were $13 \%$ in 2000 and $16 \%$ in $2013 .{ }^{43}$ 
Genetic factors such as $B R C A 1 / 2$ mutations increase the risk of ovarian cancer (especially $B R C A 2$ ). The population of Ireland and NI is considered to be genetically homogenous. A report on 2 specific $B R C A$ mutations, particularly common in Scotland and NI, showed that they account for a quarter of all mutations in these populations, suggesting that one of the founder mutations is likely to have originated in West-Central Scotland or Ireland. ${ }^{44}$ However, the researchers were unable to assess the prevalence of $B R C A$ mutations in the general population. ${ }^{44}$ In Israel, 3 common $B R C A$ mutations are present in up to $2.5 \%$ of Ashkenazi Jewish women, ${ }^{45}$ an ethnic group accounting for up to a third of the Jewish population in 2014. Whereas in other countries it is often estimated that $5 \%$ to $15 \%$ of invasive ovarian cancer is attributed to genetic mutations, ${ }^{46}$ in Israeli Jews this estimate is approximately $30 \% .{ }^{47}$ Recently, population-based screening for BRCA mutations in Ashkenazi Jewish women has been proposed in Israel instead of family history-based case finding. ${ }^{48}$ Thus, increased genetic testing in Israel may have impacted ovarian cancer incidence, as $B R C A$ mutation carriers are often advised to undergo prophylactic oophorectomy as soon as they completed their planned childbearing.

Sopik et $\mathrm{al}^{4,49}$ suggested that the decline in ovarian cancer incidence seen in the United States in recent decades might largely be a consequence of the introduction of OCs in the 1960 s and expansion of their use (from $0 \%$ to $85 \%$ ) during 1960-1990. ${ }^{4,48}$ Ireland, NI, and Israeli Jews experienced comparable trends in $\mathrm{OC}$ use, but differed with respect to other protective factors (eg, fertility and breastfeeding rates) and risk factors (eg, obesity prevalence, genetic factors). As incidence trends in Ireland and NI, countries with genetically similar populations and separate health care systems did not differ, whereas in Israel trends significantly differed ${ }^{50}$ between Jews and Arabs, 2 distinctive population groups ${ }^{51-53}$ who share the same health care system, genetic factors and individual exposures are apparently the main drivers of the observed differences, not health care parameters.

\section{Mortality Trends}

Mortality from ovarian cancer is documented as higher in Europe than East Asia countries ${ }^{53}$ with trends increasing in few countries. ${ }^{23,54,55}$ In most other countries, mortality rates are decreasing ${ }^{4,18,19,56}$ or stable. ${ }^{17,23,54}$ The current study showed significantly decreasing mortality trends during the period 1994-2013 in Ireland, NI (since 2005), and Israeli Jews, which are consistent with the observations for other high-background-mortality countries (ie, the United States, for the period 1975-2011).

Decline in cancer mortality may be attributed to decreased incidence and/or improved survival, which in itself may result from earlier detection and better treatment. ${ }^{4}$ In the case of Ireland, NI, and Israel, decreased ovarian cancer incidence is likely to be the main driver of decreasing mortality, with improved case fatality unlikely to be a significant factor. In the United States, the majority of ovarian cancer cases are diagnosed at an advanced stage, and the distribution of stage at diagnosis has not changed in parallel with the reported decrease in mortality. ${ }^{4}$ Furthermore, treatment protocols are based on international guidelines ${ }^{57}$ and are likely to be relatively uniform in the 3 countries. Our proxy for case fatality, the I/M ratio, was stable during the study period for all study groups, with the exception of Israeli Jews, in whom increased case fatality was implied. However, this finding may reflect a more rapid incidence decline compared with mortality decline (respective APCs of $-2.2 \%$ and $-1.2 \%$ ). Five-year net survival rates for the 3 countries studied, as measured by the CONCORD-2 project in 67 countries, were generally low: for the periods 1995-1999, 2000-2004, and 2005-2009, survival was, respectively, $28.1 \%, 29.6 \%$, and $32.2 \%$ in Ireland; $39.5 \%, 36.7 \%$, and $37.1 \%$ in $\mathrm{NI}$; and $38.9 \%, 40.5 \%$, and $42.0 \%$ in Israel. ${ }^{58}$

As was observed for incidence trends, no differences in mortality were noted between Ireland and NI, whereas trends for Israeli Jews and Arabs differed significantly. The current evidence suggests that the trend of decreased mortality in ovarian cancer is mostly driven by the decline in incidence. In Israeli Arabs, no change in incidence or mortality was observed.

\section{Study Strengths and Limitations}

The advantage of the current study is the use of systematically collected, validated population-based national data for cancer incidence and mortality. However, the study is ecological in nature and does not permit causal inference, although it may be helpful in hypothesis generating. In addition, annual numbers of ovarian cancer cases and deaths were low among the Israeli Arab population, but the study was sufficiently powered to demonstrate that there were, in fact, significant differences in both incidence and mortality trends between Israeli Arab and Israeli Jewish women.

\section{CONCLUSIONS}

Declining trends of ovarian cancer incidence in Ireland, $\mathrm{NI}$, and Israeli Jews are similar, with change rate greater in Israel. These trends likely reflect changing exposures to certain protective (birth rate, breastfeeding, risk reduction procedures) and risk factors (obesity prevalence), as well as differing genetic susceptibility. Ovarian cancer mortality trends in Ireland, NI, and Israeli Jews are quite comparable and mostly reflect the observed incidence decline. In contrast, Israeli Arab women, whose incidence and mortality rates are much lower compared with Israeli Jewish women, showed no evidence of decreases in incidence or mortality trends.

\section{REFERENCES}

1. World Cancer Research Fund. Ovarian cancer statistics. 2016. Available at: http://www.wcrf.org/int/cancer-facts-figures/ data-specific-cancers/ovarian-cancer-statistics. Accessed December 4, 2016.

2. Ferlay J, Soerjomataram I, Ervik M, et al GLOBOCAN 2012 v1.1, Cancer Incidence and Mortality Worldwide: IARC CancerBase No. 11 [Internet]. International Agency for Research on Cancer: Lyon, France; 2014. Available at: http:// globocan.iarc.fr. Accessed December 4, 2016.

3. Yancik R. Ovarian cancer. Age contrasts in incidence, histology, disease stage at diagnosis, and mortality. Cancer. 1993; 71(2 suppl):517-523.

4. Sopik V, Iqbal J, Rosen B, et al. Why have ovarian cancer mortality rates declined? Part I. Incidence. Gynecol Oncol. 2015;138:741-749. 
5. Buys SS, Partridge E, Black A, et al. Effect of screening on ovarian cancer mortality: the Prostate, Lung, Colorectal and Ovarian (PLCO) Cancer Screening Randomized Controlled Trial. JAMA. 2011;305:2295-2303.

6. Jacobs IJ, Menon U, Ryan A, et al. Ovarian cancer screening and mortality in the UK Collaborative Trial of Ovarian Cancer Screening (UKCTOCS). Lancet. 2016;387:945-956.

7. Ireland Health Service Executive Web site. Available at: www. hse.ie. Accessed December 4, 2016.

8. Health and Social Care in Northern Ireland Web site. http:// www.hscni.net. Accessed December 4, 2016.

9. Segel S. Can universal healthcare work? A look at Israel's successful model. In: Physicians News Digest. 2009. Available at: https://physiciansnews.com/2009/10/01/can-universalhealthcare-work-a-look-at-israels-successful-model/. Accessed December 4, 2016.

10. Central Statistics Office Ireland database. Available at: www. cso.ie/en/statistics. Accessed December 4, 2016.

11. Northern Ireland Statistics and Research Agency (NISRA) database. Available at: www.nisra.gov.uk. Accessed December 4, 2016.

12. Israel Central Bureau of Statistics (CBS) database. Available at: www.cbs.gov.il. Accessed December 4, 2016.

13. Cancer Incidence in Five Continents, Volume III. Waterhouse J, Correa P, Muir C, et al, eds. Lyon, France: IARC; 1976.

14. National Cancer Registry Ireland. Cancer in Ireland 1994-2011: annual report of the National Cancer Registry 2014. 2014. Available at: http://www.ncri.ie/sites/ncri/files/pubs/ annual\%20report\%202014.pdf. Accessed December 4, 2016.

15. Fishler Y, Shetrit A, Barchana M, et al. Assessment of the completeness of the Israel Cancer Registry database-methods and findings. Israel Center for Disease Control, Ministry of Health; 2003. Available at: http://bit.ly/1nvgtfQ. Accessed December 4, 2016 [Hebrew].

16. Joinpoint Regression Program, Version 411. Statistical Research and Applications Branch, National Cancer Institute; Bethesda, MD;2014.

17. Marugame T, Hirabayashi Y. Comparison of time trends in ovary cancer incidence (1973-1997) in East Asia, Europe, and the USA, from Cancer Incidence in Five Continents Vols IV-VIII. Jpn J Clin Oncol. 2007;37:802-803.

18. Trétarre B, Molinié F, Woronoff AS, et al. Ovarian cancer in France: trends in incidence, mortality and survival, 1980-2012. Gynecol Oncol. 2015;139:324-329.

19. Ør Knudsen A, Schledermann D, Nyvang GB, et al. (2016). Trends in gynecologic cancer among elderly women in Denmark, 1980-2012. Acta Oncol 55 :65-73.

20. Elit L, Bondy SJ, Chen Z, et al. A tale of two time periods: ovarian cancer trends in Ontario. Curr Oncol. 2007; 14:57-60.

21. Bhurgri Y, Shaheen Y, Kayani N, et al. Incidence, trends and morphology of ovarian cancer in Karachi (1995-2002). Asian Pac J Cancer Prev. 2011;12:1567-1571.

22. Dhillon PK, Yeole BB, Dikshit R, et al. Trends in breast, ovarian and cervical cancer incidence in Mumbai, India over a 30-year period, 1976-2005: an age-period-cohort analysis. Br J Cancer. 2011;105:723-730.

23. Huang Z, Zheng Y, Wen W, et al. Incidence and mortality of gynaecological cancers: secular trends in urban Shanghai, China over 40 years. Eur J Cancer. 2016;63:1-10.

24. Yahata T, Banzai C, Tanaka K. Niigata Gynecological Cancer Registry. Histology-specific long-term trends in the incidence of ovarian cancer and borderline tumor in Japanese females: a population-based study from 1983 to 2007 in Niigata. J Obstet Gynaecol Res. 2012;38:645-650.

25. O'Mahony L, Liddy AM, Barry M, et al. Hormonal contraceptive use in Ireland: trends and co-prescribing practices. Br J Clin Pharmacol. 2015;80:1315-1323.

26. Israel Center for Disease Control. Health status in Israel 2010. Publication 333, August 2011, Jerusalem, Israel [Hebrew]. Available at: http://www.health.gov.il/ PublicationsFiles/Health_Status_in_Israel2010.pdf. Accessed December 4, 2016.

27. Sayers G, Thornton L, Corcoran R, et al. Influences on breast feeding initiation and duration. Ir J Med Sci. 1995;164: 281-284.

28. Ladewig EL, Haues C, Browne J, et al. The influence of ethnicity on breastfeeding rates in Ireland: a cross-sectional study. J Epidemiol Community Health. 2014;68:356-362.

29. UK Health and Social Care Information Centre. Infant feeding survey-UK 2010: chapter 2, incidence, prevalence and duration of breastfeeding. Available at: http://www.hscic.gov. uk/catalogue/PUB08694/ifs-uk-2010-chap2-inc-prev-dur.pdf. Accessed December 4, 2016.

30. MABAT INFANT. National Health and Nutrition Survey. Birth to age 2 years, 2009-2012 Israel Center for Disease Control. Publication 352, January 2014. Jerusalem, Israel [Hebrew]. Available at: http://www.health.gov.il/PublicationsFiles/mabat_ 352.pdf. Accessed December 4, 2016.

31. Smith AS, Hourihane JO'B, Kenny LC, et al. Duration of breast feeding in an Irish birth cohort study. Midwifery. 2015;31:904-911.

32. World Health Organization. Global Health Observatory Data Repository. Exclusive breastfeeding under 6 months. Data by country. Available at: http://apps.who.int/gho/data/view.main. NUT1730. Accessed December 4, 2016.

33. Usher C, Teeling M, Bennett K, et al. Effect of clinical trial publicity on HRT prescribing in Ireland. Eur J Clin Pharmacol. 2006;62:307-310.

34. Rossouw JE, Anderson GL, Prentice RL, et al. Risks and benefits of estrogen plus progestin in healthy postmenopausal women: principal results From the Women's Health Initiative randomized controlled trial. JAMA. 2002;288:321-333.

35. Beral V, Million Women Study Collaborators. Breast cancer and hormone replacement therapy in the Million Women Study. Lancet. 2003;362:419-427.

36. Watson J, Wise L, Green J. Prescribing of hormone therapy for menopause, tibolone, and bisphosphonates in women in the UK between 1991 and 2005. Eur J Clin Pharmacol. 2007;63:843-849.

37. Keinan-Boker L, Dichtiar R, Garty N, et al. Prevalence and correlates of hormonal therapy among Israeli women in the post-WHI era. Maturitas. 2005;52:364-373.

38. Silverman BG, Kokia ES. Use of hormone replacement therapy, 1998-2007: sustained impact of the Women's Health Initiative findings. Ann Pharmacother. 2009;43:251-258.

39. Irish Health Web site. Available at: http://www.irishhealth.com/ article.html?id=19452. Accessed December 4, 2016.

40. IPSOS MRBI. Healthy Ireland Survey 2015. Summary of Findings. Dublin, Ireland: The Stationery Office; 2015.

41. Lifestyle Report. Portadown, Northern Ireland: Southern Health and Social Service Board N. Ireland; 1992.

42. Dee A, Callinan A, Doherty E, et al. Overweight and obesity on the island of Ireland: an estimation of costs. BMJ Open. 2015;5:e06189. 
43. OECD library. Available at: http://www.oecd-ilibrary.org/ docserver/download/8115071 ec019.pdf?expires= $1468322059 \& \mathrm{id}=\mathrm{id} \&$ accname $=$ guest $\&$ checksum $=$ 461EE7DEBA89BC1BC7823FC4ED91B7CB. Accessed December 4, 2016.

44. The Scottish/Northern Irish BRCA1/BRCA2 Consortium. $B R C A 1$ and BRCA2 mutations in Scotland and Northern Ireland. Br J Cancer. 2003;88:1256-1262.

45. Struewing IP, Hartge P, Wacholder S, et al. The risk of cancer associated with specific mutations of BRCA1 and BRCA2 among Ashkenazi Jews. $N$ Engl J Med 1997;3361401-1408.

46. Ramus SJ, Gayther SA. The contribution of BRVA1 and BRCA2 to ovarian cancer. Mol Oncol. 2009;3:138-150.

47. Hirsch-Yechezkel G, Chetrit A, Lubin F, et al. Population attributes affecting prevalence of $B R C A$ mutation carriers in epithelial ovarian cancer cases in Israel. Gynecol Oncol 2003;89:494-498.

48. Manchanda R, Legood R, Burnell M, et al. Cost-effectiveness of population screening for $B R C A$ mutations in Ashkenazi Jewish women compared with family history-based testing. $J$ Natl Cancer Inst. 2014;107:380.

49. Sopik V, Iqbal J, Rosen B, et al. Why have ovarian cancer mortality rates declined? Part II. Case fatality. Gynecol Oncol. 2015;138:750-756.

50. Israel National Cancer Registry Web site. Available at: http:// www.health.gov.il/unitsoffice/hd/icdc/icr/cancerincidence/ pages/about.aspx. Accessed December 4, 2016.
51. Shpitz B, Millman M, Ziv Y, et al. Predominance of younger age, advanced stage, poorly-differentiated and mucinous histology in Israeli Arab patients with colorectal cancer. Anticancer Res. 2006;26(1B):533-537.

52. Keinan-Boker L, Baron-Epel O, Fishler Y, et al. Breast cancer trends in Israeli Jewish and Arab women, 1996-2007. Eur J Cancer Prev. 2013;22:112-120.

53. Atzmon I, Linn S, Portnov BA, et al. Lower cancer rates among Druze compared to Arab and Jewish populations in Israel, 1999-2009. J Relig Health. 2017;56:741-754.

54. Hirabayashi Y, Marugame T. Comparison of time trends in ovary cancer mortality (1990-2006) in the world, from the WHO mortality database. Jpn J Clin Oncol. 2009;39:860-861.

55. Sharifian A, Pourhoseingholi MA, Norouzinia M, et al. Ovarian cancer in Iranian women, a trend analysis of mortality and incidence. Asian Pac J Cancer Prev. 2014;15: 10787-10790.

56. Kmietowicz Z. Death rate from ovarian cancer in England has fallen by a fifth since 2001. BMJ. 2012;345:e7861.

57. Ledermann JA, Raja FA, Fotopoulou C, et al. Newly diagnosed and relapsed epithelial ovarian carcinoma: ESMO clinical practice guidelines. Ann Oncol. 2013;24(suppl 6):vi24-vi32.

58. Allemani C, Weir HK, Carreira H, et al. Global surveillance of cancer survival 1995-2009: analysis of individual data for $25,676,887$ patients from 279 population-based registries in 67 countries (CONCORD-2). Lancet. 2015;385:977-1010. 